\title{
Real-Time Ultrasound Guided the New Standard Technique for Percutaneous Dilatational Tracheostomy(PDT)
}

\author{
Mohsen Ziyaeifard ${ }^{1}$; Ziya Totonchi ${ }^{1, *}$ \\ ${ }^{1}$ Rajaie Cardiovascular, Medical and Research Center, Iran University of Medical Sciences, Tehran, Iran \\ ${ }^{*}$ Corresponding author: Ziya Totonchi, Rajaie Cardiovascular, Medical and Research Center, Iran University of Medical Sciences, Tehran, Iran. Tel: +98-2123922153, Fax: +98-22663293, \\ E-mail:ziya189@yahoo.com
}

Received: October 18, 2014; Revised: November 4, 2014; Accepted: November 22, 2014

Keywords:Ultrasound; Percutaneous; Dilatational Tracheostomy

Several studies demonstrated that percutaneous dilatational tracheostomy (PDT) is a safe, easy, low-cost and minimally-invasive bedside method with numerous known advantages more than surgical tracheostomy such as fewer adjacent tissue injury, lesser bleeding risk, wound infectivity (morbidity) and mortality $(1,2)$. PDT technique is usually done with the help of fiberscope guide for more security and accurateness of the practice. Blind PDT technique has several disadvantages including failure to recognize accurate point of opening and position of tracheostomy pipe, chance of damage to nearby structures and false passageway. PDT with bronchoscopic guide can lessen these hesitations (3). However, it has its own difficulties such as disorder of ventilation - particularly in patients with elevated of Positive End-Expiratory Pressure (PEEP) - and considerable hypercarbia through risk of increased intracranial pressure. Therefore, pa- tients with spinal cord or head damage may weakly tolerate this method $(2,3)$.

Recently, portable ultrasonography is used in these cases for pre-intubation evaluation of upper airway, postintubation confirmation of endo-tracheal tube position, and extubation tracheal tube result (4). However, there is limited information and observational study data that supports the efficacy and safety of ultrasonography guided of PDT $(5,6)$.

Ultrasonography has numerous advantages. It is individually portable, reliable, safe, pain-free, low-cost and simply available (7). Portable and real-time ultrasound has further advantage for facilitating the clinicians toward identifying the needle passageway by presentation dislocation of tissues in front of the needle $(6,8)$ (Figure 1$)$. Sharp groove in anterior tracheal wall with incursion of needle and following flattening might be more visible by this procedure (5).

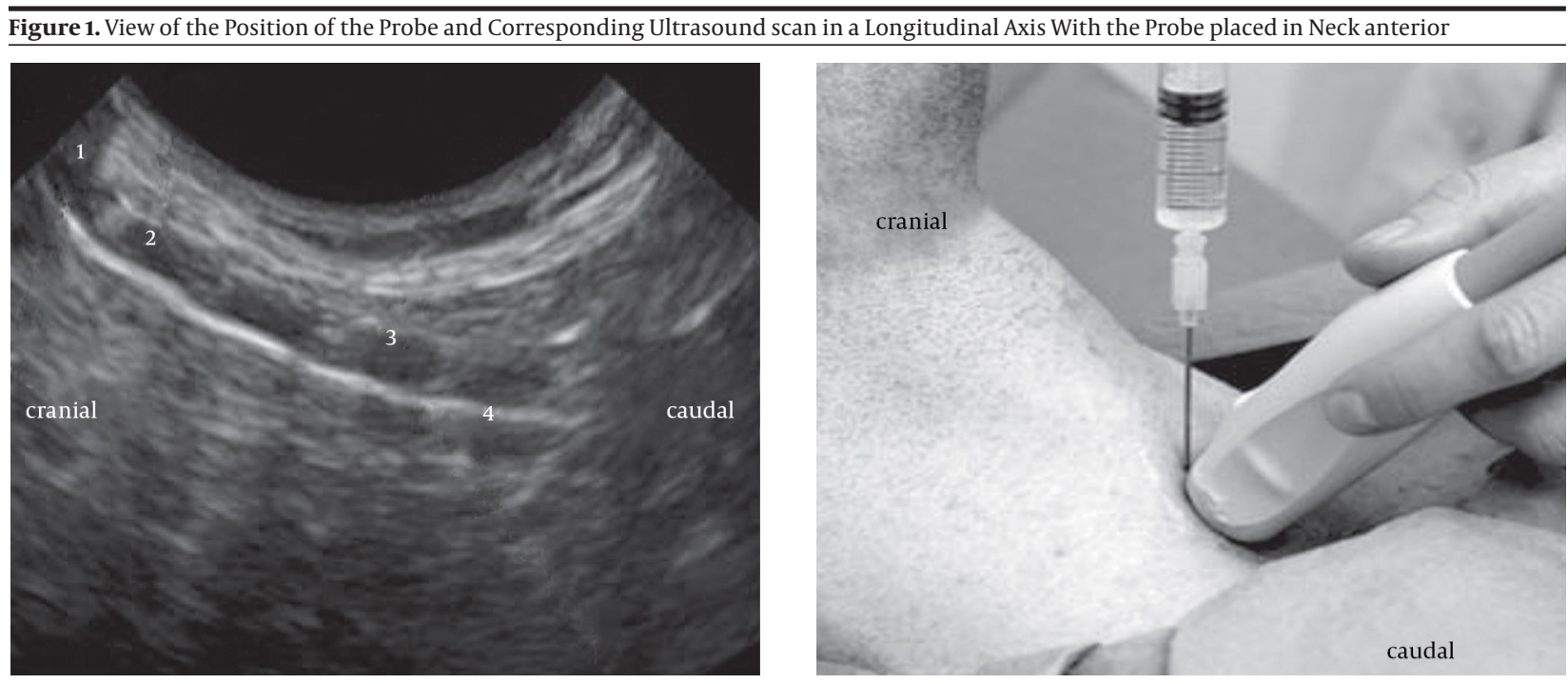

This figure shows Thyroid cartilage (1), Cricoid cartilage (2), second tracheal cartilage ring (3), and the echogenic line is consistent with an air-tissue interface at the anterior tracheal wall. The cartilages are echolucent. Location of needle insertion is between first and second cartilage ring.

Copyright (C) 2015, Iranian Society of Regional Anesthesia and Pain Medicine(ISRAPM). This is an open-access article distributed under the terms of the Creative Commons Attribution-NonCommercial 4.0 International License (http://creativecommons.org/licenses/by-nc/4.0/) which permits copy and redistribute the material just in noncommercial usages, provided the original work is properly cited. 
Box 1. Complications Associated to Conventional Procedure or Non-use of Ultrasound in PDT

\begin{tabular}{l}
\hline Hemorrhage \\
\hline Failure of airway in procedure \\
\hline Early dislodgement \\
Infectivity \\
\hline Pneumomediastinum \\
\hline Pneumothorax \\
\hline Failure to complete procedure \\
\hline Switch to surgical tracheostomy /require for change of tracheostomy \\
\hline Posterior wall damage \\
Tracheomalacia, tracheal stenosis \\
Tracheo-cutaneous, tracheo-innominate, and tracheo-esophageal fistula \\
\hline
\end{tabular}

Real- time ultrasound guided PDT preserves as a safe and cost-effective bedside method for superior use in critical ill patients, particularly in patients with morbid obesity and spinal damage $(6,7)$.

Michigan researchers have shown that this technique can reduce the rate of major complications. Some studies showed that the complications are 10 times less in patients who received ultrasonography guided PDT comparing with patients that had conventional procedure approach (Box1) $(9,10)$.

Nasir Bhatti, MD (director of adult Tracheostomy and Airway Service in the Hospital affiliated to Johns Hopkins University, Baltimore, USA) supported the use of ultrasound guided PDT by non-surgeons; including pulmonologists and intensivists performing arts of PDTs (10).

Ultrasound guided PDT facilitate clinicians to preserve adjacent structures $r$; demonstrate the guide wire location and the correct level of cannula. It also enables clinicians to assess the space between the anterior tracheal wall and the skin, to evaluate extends length of tube, and suitably put the endo-tracheal tube in the correct position. However, randomized clinical trials are required to evaluate ultrasound guided PDT as if can be a standard technique, similar to the previous method which is used in central venous catheter placement (10-12).

\section{Acknowledgements}

Rajaee Heart Center, Department of Anesthesiology faculty cooperation that we appreciate their support.

\section{References}

1. Delaney A, Bagshaw SM, Nalos M. Percutaneous dilatational tracheostomy versus surgical tracheostomy in critically ill patients: a systematic review and meta-analysis. Crit Care. 2006;10(2):R55.

2. Youssef TF, Ahmed MR, Saber A. Percutaneous dilatational versus conventional surgical tracheostomy in intensive care patients. $N$ Am J Med Sci. 2011;3(11):508-12.

3. Rajajee V, Fletcher JJ, Rochlen LR, Jacobs TL. Real-time ultrasoundguided percutaneous dilatational tracheostomy: a feasibility study. Crit Care. 2011;15(1):R67.

4. Rodriguez SJ, Esteves LE. Real-time ultrasound-guided percutaneous dilatational tracheostomy. Crit Care. 2011;15(5):443.

5. Chacko J, Nikahat J, Gagan B, Umesh K, Ramanathan M. Real-time ultrasound-guided percutaneous dilatational tracheostomy. Intensive Care Med. 2012;38(5):920-1.

6. Joelsons D, Ho YL, Park M. Ultrasound-guided percutaneous tracheostomy: a feasible alternative for tetanus patients. Crit Care. 2014;18(3):441.

7. Mehta Y. Percutaneous dilatational tracheostomy: Guided well with real-time ultrasound. Indian J Crit Care Med. 2013;17(6):335-6.

8. Kleine-Brueggeney M, Greif R, Ross S, Eichenberger U, Moriggl B Arnold A, et al. Ultrasound-guided percutaneous tracheal puncture: a computer-tomographic controlled study in cadavers. $\mathrm{Br} J$ Anaesth. 2011;106(5):738-42.

9. Mitra S, Kapoor D, Srivastava M, Sandhu H. Real-time ultrasound guided percutaneous dilatational tracheostomy in critically ill patients: A step towards safety! Indian J Crit Care Med. 2013;17(6):367-9.

10. Kate OR. Ultrasound: The New Standard of Care for Percutaneous Dilatational Tracheostomy? J Clin Anesthesiol. 2014;40(3).

11. Dinh VA, Farshidpanah S, Lu S, Stokes P, Chrissian A, Shah H, et al. Real-time sonographically guided percutaneous dilatational tracheostomy using a long-axis approach compared to the landmark technique. J Ultrasound Med. 2014;33(8):1407-15.

12. Ziyaeifard M, Azarfarin R. Ultrasound is a new and reliable technique for central venous cannulation. Res Cardiovasc Med. 2014;3(3):e17328. 